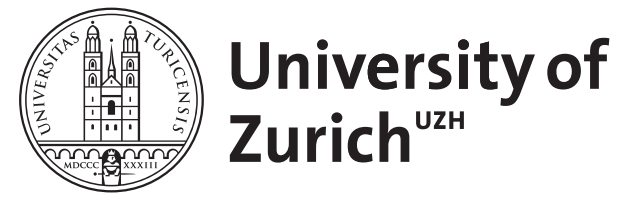

Zurich Open Repository and Archive

University of Zurich

University Library

Strickhofstrasse 39

CH-8057 Zurich

www.zora.uzh.ch

Year: 2007

\title{
Typology in the 21st century: major current developments
}

Bickel, Balthasar

DOI: https://doi.org/10.1515/LINGTY.2007.018

Posted at the Zurich Open Repository and Archive, University of Zurich

ZORA URL: https://doi.org/10.5167/uzh-49002

Journal Article

Published Version

Originally published at:

Bickel, Balthasar (2007). Typology in the 21st century: major current developments. Linguistic Typology, 11:239-251.

DOI: https://doi.org/10.1515/LINGTY.2007.018 


\section{Typology in the 21st century: Major current developments}

BALTHASAR BICKEL

\section{Typology as a discipline}

In the past century, typology was mostly used as an alternative method of pursuing one of the same goals as generative grammar: to determine the limits of possible human languages and, thereby, to contribute to a universal theory of grammar. The paradigm result was the absolute universal law that would rule out as linguistically impossible what would seem logically imaginable, e.g., a language with a gender distinction exclusively in the 1st person singular.

Over the past decade, typology has begun to emancipate itself from this goal and to turn from a method into a full-fledged discipline, with its own research agenda, its own theories, its own problems. What has reached center-stage is a fresh appreciation of linguistic diversity in its own right, and the new goal of typology is the development of theories that explain why linguistic diversity is the way it is - a goal first made explicit by Nichols's (1992) call for a science of population typology, parallel to population biology. Instead of asking "what's possible?", more and more typologists ask "what's where why?". Asking "what's where?" targets universal preferences as much as geographical or genealogical skewings, and results in probabilistic theories stated over properly sampled distributions. Asking "why?" is based on the premises that (i) typological distributions are historically grown and (ii) that they are interrelated with other distributions.

Understanding distributions as historically grown goes back at least to Greenberg's (1965, 1978) and Givón's (1979) early calls for diachrony in typology and means that synchronic distributions, whether universal preferences or geographical clusterings, are seen as the product of type transitions and diachronic processes in general ${ }^{1}$ (also see Bybee 1988 and Hall 1988 for strong argu-

1. Some typologists (e.g., Plank \& Schellinger 2000) reserve the term diachronic universal (pref- 
mentation in this direction). It is a matter of current debate whether universal preferences result from preference principles that guide (or "select") the result of diachrony (as assumed by, e.g., Nettle 1999, Kirby 1999, or Haspelmath 1999 ) or from locally motivated preferred pathways of change (as in the work of, e.g., Croft 2000, Bybee 2001, Blevins 2004, and in much of grammaticalization theory). On either view, the current distribution is understood as the product of history and the objects of inquiry are probabilities of change and the principles behind them.

Understanding typological distributions as interrelated with, and partly grounded in other distributions reflects the finding that linguistic structures tend to be systematically interrelated among themselves and with other anthropological patterns, understood in a broad sense ranging from social to cognitive to genetic structures. Some of these findings gave rise to theories that predict close correlations between universal preferences in structure with universal preferences in cognition and communication (e.g., processing preferences, as most extensively argued for by Hawkins 2004), and these have been at the top of typology's agenda. But in line with the new enlarged perspective on distributions, correlations of local structures with local preferences in cognition or social interaction have gained increasing attention - in most cases through wholeheartedly interdisciplinary research. This is illustrated first of all by the rapid growth in linguistic relativity research over the past decade (e.g., Lucy 1992, Gumperz \& Levinson (eds.) 1996, Niemeier \& Dirven (eds.) 2000, Levinson 2003, Bickel 2003, Gentner \& Goldin-Meadow (eds.) 2003, Roberson et al. 2005) and in the analysis of the local cultural underpinnings of specific linguistic structures (e.g., Bickel 2000, Enfield (ed.) 2002, Evans 2003). Further, psycholinguists have started to systematically study and control for typological variance in processing and acquisition through rigorous comparative research (for neurolinguistic studies, cf. Bornkessel et al. 2005, Bornkessel \& Schlesewsky 2006; for acquisition research, cf., e.g., Berman \& Slobin (eds.) 1994, Bowerman \& Levinson 2001, Lieven \& Stoll in press). And last but not least, most typological distributions reveal distinct geographical patterns, and these can only be understood against models of population movements and language contact, systematically informed by what is known from historical anthropology, genetics, and archeology (e.g., Nichols 1992, 1997, Fortescue 1998, Bickel \& Nichols 2005, 2006, Dunn et al. 2005).

erence) for cases where an implicational universal directly translates into diachrony (e.g., "OV preferentially implies postpositions (rather than prepositions)" translates into "O-V preferentially develops into NP-P (rather than P-NP)"). Type transition preferences, by contrast, summarize all historical factors that lead from a universally dispreferred to a preferred pattern (e.g., from VO order with prenominal to VO order with postnominal relative clauses). 
In order to capture and test distributions, typologists develop variables that measure similarities and differences between languages. ${ }^{2}$ Typological variables are (if well-crafted) crosslinguistically applicable in formally precise ways, entail analyses of language-specific structures with clear predictions, and define an explicit ontology of similarities and differences (a tertium comparationis). In order to explain why the values of these variables are distributed in the world as they are, typologists develop theories of areal skewings or universal preferences grounded in various anthropological (including psychological) domains. As argued by Dryer (1997), the variables and explanatory theories developed in typology have ontological commitments to language-specific structures and to observable similarities between them, but, unlike work that aims at defining the absolute conditions of human language, there is no necessary commitment to universal entities in grammar (a "Universal Grammar", UG) beyond the most general design features. Moreover, typological theories are about probabilities of distributions, not about possibilities, and so they go far beyond the UG goal of defining what is possible (Bell 1978, Newmeyer 1998, 2005, Dryer 1998, Haspelmath 2004, Nichols 2007).

Would modern typology have more in common with UG research, if UG parameters could directly predict observable distributions, for example by conditioning probabilities through implicational chains of absolute univerals? Baker (2002), for example, proposes to predict the universal dispreference against VSO orders against both SVO and SOV orders from a set of three binary parameters defined in such way that $\mathrm{V}$-initial order can only arise when all three parameters have a specific value, while the other orders are consistent with all other $\left(2^{3}-1\right)$ logically possible combinations of parameter settings. While I concur with Baker \& McCloskey (2007) that the success of this approach is an open issue, experience from recent work in typology leads one to suspect an inherent shortcoming: the observable distributions are substantially influenced by population history, and this makes it fundamentally problematic to try and predict them by principles of grammar alone. The worldwide distribution of verb-initial orders, to keep with Baker's example, is contingent on population history and therefore shows clear areal patterns: there is a statistically highly significant and historically fairly stable frequency increase around the Pacific (Nichols 1992, Bickel \& Nichols 2006), and there are narrower peaks in the eastern Rift Valley and in insular northwest Europe (the latter possibly with an areal-historical connection to Northern Africa, see Gensler 1993). This makes it likely that not only the geographical locations but also the sheer base frequencies are driven by historical processes beyond what absolute UG parameters can possibly model. In Baker's example: had the peopling of Eurasia and

2. In terms of publication output this is the most prominent kind of typological day-to-day business. And it is the foundation for everything else, cf. Section 3. 
the Americas followed a different course, V-initial languages might now be the universal default.

The general picture emerging from this is that UG research is largely irrelevant for modern typology. Newmeyer $(1998,2004)$ and Haspelmath (2004) add that, in turn, typology is also irrelevant for UG research. This may be true under some conceptions of UG, but not if a universal theory of grammar aims at typological adequacy (e.g., Dik 1978, VanValin \& LaPolla 1997, Baker \& McCloskey 2007, and generally in Optimality Theory) in the sense that the ontology of typological variables - and, crucially, not their distributions - should fall out from the architecture of the theory. It is also sometimes suggested that universal theories are well-advised to check their claims against more than one existing language (e.g., Van Valin \& LaPolla 1997, Baker \& McCloskey 2007), and indeed many universal claims have been falsified by newly described languages (for records, see the Konstanz Universals Archive and Raritätenkabinett, cf. Plank \& Filimonova 2000, Plank \& Mayer 2006, Plank (ed.) 2003). But extending our dataset by analyzing undescribed languages is not and should not be exclusively the task of typologists - especially not in these times of mass extinction of languages!

To conclude, typology has shifted from a method used in UG research to a discipline seeking to answer "what's where why?" by developing sets of variables and probabilistic theories explaining the distribution of these variables. But not everything has changed: most prominently, as in the past, typologists find it useful to develop variables as close to observable data ${ }^{3}$ as possible and close to fieldwork. This is first of all a practical decision, because very abstractly defined variables are difficult to survey in sufficiently large samples, and samples can often only be completed by doing additional fieldwork. But the decision is also theoretically motivated because the definition of abstract variables is commonly tied to some UG model that itself seeks to abstract away from linguistic diversity, and less so to the kinds of anthropological hypotheses of interest. ${ }^{4}$

\section{What has brought us here?}

The overt signs of typology maturing into a discipline are the fact that the field has now dedicated journals, professional associations, academic chairs,

3. Observable means that we have operationalized criteria to decide what some structure is in a specific language. It does not mean "surface", as opposed to "underlying". Typology, like any other kind of linguistics, is about structural patterns, not about unanalyzed surface lists or rough meaning guesses (cf. Nichols 2007, Hyman 2007)

4. A similar trend away from abstract, UG-derived discussion or measurement of linguistic structure can also be observed in psycholinguistics and has always been characteristic of linguistic anthropology. 
and research centers. But what are the intellectual developments that lead to the new perspective on typology? I propose that two major developments are at the source: the discovery of what one might call universal areality and major advances in methodology.

\subsection{Universal areality}

Since the late 1980s and most prominently through the work of Dryer (1989, 1992) and Nichols (1992), it has become clear that hardly any typological variable, and only some combinations thereof, is evenly distributed in the world. Most distributions are subject to non-accidental geographical skewing. An example: I tested the hypothesis that verb-final or free word order correlates with having case or adposition markers distinguishing transitive subjects and objects (cf. Konstanz Universals Archive \#447) against a large dataset $(N=383)$ combining information from WALS (chapters by Comrie 2005 and Dryer 2005) and AUTOTYP (Bickel \& Nichols 2007). ${ }^{5}$ The association is significant (Fisher's Exact Test, $p=.003$ ), also when the data are adjusted for genealogical inflation effects by applying the methods proposed in Dryer (1989) or Bickel (2007). This replicates earlier results by Dryer (2002) on a partially different and smaller dataset $(p<.001, N=257)$. But if ones examines the data continent-by-continent, it turns out that the association is significant only in Eurasia ( $p=.04, N=48$ ), a region of independently known areality (Jakobson 1931, Nichols 1992). Everywhere else it can be predicted from the base frequencies of the two variables. Such examples can easily be multiplied and underline Dryer's (1989) warning that a statistical association does not necessarily support a universal preference hypothesis unless geographical factors (and other confounding factors, see below) are controlled for.

But even when a pattern has seemingly solid universal support, such as the association between OV order and postpositions, or VO order and postnominal relative clauses, the observed distributions can only be fully understood by probing into areal developments. For deviations from such universal trends (e.g., OV and prepositions in Iranian, see Stilo 2005, or VO and prenominal relative clauses in Sinitic, see Dryer 2003) tend to again reveal areal patterns. They typically concentrate in what Stilo $(1987,2005)$ calls buffer zones between spread areas with opposite typological profiles (Masica's 1976 "IndoAltaic" vs. Southwest Asia in the case of Iranian; Indo-Altaic vs. Southeast Asia in the case of Sinitic). Such contact pressure can affect distributions because it competes with language-internal factors (e.g., parsing ease) in historical development.

5. For the case data, there was only one mismatch out of 100 languages coded in both WALS and AUTOTYP. Mismatches in word order coding were 9 out of 238, i.e., less than $4 \%$. The results reported here are not sensitive to which coding is chosen in the case of mismatches. 
This does not come as a surprise. We know that languages shift their typological profiles in language contact (from language shift to bilingualism) and that language contact is a near-universal given. But contact and type spread is of course not the sole factor driving distributions. Another important factor is relative isolation at the fringes of major spreads (typological enclaves; see Bickel $\&$ Nichols 2003), and this too can produce deviations from universal (or, for that matter, macro-areal) trends, often with remarkable historical persistence. Nettle (1999) adds population size as a factor favoring rarities, assuming that variants more rapidly stabilize in small populations.

The discovery of areality effects all over has had two immediate consequences that reinforced the historical turn in typology noted above.

First of all, pervasive areality effects make clear that many current typological distributions can only be understood as the result of actual (pre-)history, both local and global. In turn, typological distributions provide a plethora of historical signals waiting for exploration and comparison with findings from other anthropological and historical disciplines.

Second, the most plausible available explanations of statistically significant macro-areas, such as those around the Pacific, or those covering Eurasia (Nichols 1992, 1997, Nichols \& Peterson 1996, Fortescue 1998, Bickel $\&$ Nichols 2003, 2005) suggest that they are the surviving traces of distributions that were formed at early periods of large-scale population and language spreads. But if distributions can survive as long as some would seem, this, as argued by Maslova (2000), substantially raises the threshold above which we are now ready to accept universals that are due to the nature of language rather than to the nature of human population history. An association of variables (e.g., NP and PP order) must then not only be statistically significant in a representative sample ${ }^{6}$ and independent of known geographical and genealogical affiliation (Dryer 1989, Perkins 1989), but it must also be shown to be independent of earlier (or even initial) stages at which there could have been significant skewing at work. In other words, associations can be taken to reflect strictly linguistic universals only if they can be shown to be sufficiently instable historically that we can assume a stationary distribution in currently observable data. This again requires a fundamentally diachronic understanding of what causes typological distributions, viz., different type shift probabilities.

6. Prospects might not be as bright as was generally believed in the 20th century: Bakker (2004) finds considerably less than $1 \%$ of all logically possible correlations among the variables in The World Atlas of Language Structure (Haspelmath et al. (eds.) 2005) to be statistically significant, and only a fraction of these to be linguistically meaningful! 


\subsection{Progress in methodology}

No doubt due to general technological advances, the past decade has seen an explosion in large typological databases. There are currently about two dozen research groups worldwide involved in developing databases (for projects in Europe, see the Language Typology Resource Centre, http://www.lotschool.nl/ Research/ltrc), and the large international collaboration behind The World Atlas of Language Structures (Haspelmath et al. (eds.) 2005) has spawned additional database work. Large datasets almost invariably reveal exceptions to universals, and this, together with a substantial increase of newly described languages and assisted by prominent conceptual argumentation (e.g., Dryer 1998, Croft 2002: Chapter 8), has practically done away with notions of absolute universals and impossibilities. Modern studies of typological distributions involve statistical methods, from association tests (cf. Cysouw 2005 for recent review) to multivariate scaling methods (e.g., Levinson et al. 2003, Croft \& Poole 2004). On the side of the ever more important historical studies, typology has seen the introduction of new data aggregation methods (e.g., the Isopleth Method, see van der Auwera 1998), statistical testing strategies (e.g., Predictive Areality Theory, see Bickel \& Nichols 2006), stability metrics (Wichmann \& Kamholz 2007), and phylogenetic methods from biology (e.g., Dunn et al. 2005). Current attempts to integrate Geographical Information Systems bring hope for yet further progress in this domain.

One common property of all these methods is that they work with narrowly defined variables, instead of the gross types ("active language", "agglutinative language") of classical holistic typology, or categorical notions of a Sprachbund. The general assumption is that if there are large-scale connections between linguistic structures, or between linguistic structures and geography, they consist in probabilistic (and therefore exception-ridden) correlations between independently measured variables; they are not expected to follow from absolutely defined or "ideal" types. In a similar vein, modern typology has moved away from typologizing entire languages and instead takes individual structural patterns (constructions, rules, constraints, etc.) as comparanda. Linguistic diversity is captured by large sets of fine-grained variables, not by grand type notions.

The analysis of such variables poses statistical problems shared by other historical population sciences - most prominently, we have access to only much less than $1 \%$ of all languages that have ever been spoken by our species, and so the current population, with all its historically-grown distributional biases, will always be overrepresented in our samples. Moreover, in typological sampling, we typically attempt exhaustive and well-balanced coverage of known genealogical diversity, so that signals of universal preference or areal population history can be told apart from relatively recent inheritance effects. But 
exhaustive sampling makes classical statistical methods mathematically meaningless. In response to these problems, typologists are now adopting MonteCarlo and exact methods, and first steps have also been undertaken towards randomization-based reliability tests on coding (Janssen et al. 2006). Unlike classical methods, which presuppose random sampling from a normally distributed population, these methods do not support statistical inference to an underlying population of all human languages. All statistical inference is limited to the current sample at hand, and the null hypothesis of the test is that an observed skewing in some dataset can be predicted from the margin totals of the same dataset - not that the observed dataset is randomly sampled from a total population without the observed skewing.

But this fits well with the new emphasis on "what's where?", and challenges once more the use of typology in the quest of defining the absolute limits of human language.

\section{Challenges ahead: Quantitative typology and the analysis of individ- ual structures}

Large-scale quantitative research is often met with suspicion by typologists seeking to compare individual linguistic structures in close detail in a small number of languages. However, it seems to me that current advances in quantitative research in fact lead to an unexpected convergence of interests.

As noted above, research on areal and genealogical signals in typological distributions needs ever larger and ever more fine-grained sets of variables coded in databases. Traditional descriptive variables such as "has incorporation" vs. "has no incorporation", however, are much too coarse and lump together large sets of variables that have their own, often independent, distributions and historical profiles, e.g., concerning specificity, topicality, and cardinality of reference, morphological and phonological coherence, phrasal expansion possibilities, grammatical relations status, argumenthood, etc. This is precisely the same conclusion that field linguists repeatedly arrive at when they try to pin down a newly encountered phenomenon. A very common experience is that the new phenomenon does not quite fit with what is called, say, "incorporation" in another language or, for that matter, a textbook. Things look often similar, but never identical. ${ }^{7}$

Other than giving up comparative research altogether, the traditional answer to this has mostly consisted in trying to fix a universal (technically known as "crosslinguistically viable") definition of "incorporation" (or whatever), often triggering heated debates. But unless the definition follows from first principles

7. For a recent real-world example of "quasi-incorporation”, see Bickel et al. (2007). 
that everybody agrees on (such as the first principles proposed in any of the named theories of linguistic description), there remains a sense of abitrariness in such definitions, and, worse, a sense that those languages which happen to be studied by the most widely read linguists end up closest to the universal definition (often then said to provide the "prototype" of the phenomenon). Still worse, by subsuming structures from many different languages under the same definition, typology ends up reducing diversity rather than measuring it. In the end, the discipline defeats its own purpose!

A promising but as yet under-explored way out of this impasse is suggested by just the same as what is need by quantitative typology anyway: finer-grained variables. Instead of trying to decide whether structure $S$ in language $L$ is or is not incorporation, one codes $S_{L}$ for a set of maximally fine-grained variables, just as large as to capture all that one knows about $S_{L}$ (e.g., has generic reference: yes/no; prohibits permutation: yes/no; subcategorizes for a stem class: yes/no, must be adjacent to another stem: yes/no; satisfies argument slots: yes/ no, triggers agreement: yes/no, or "NA" if the language has no agreement to begin with, etc.). Because they are maximally fine-grained, they involve less controversial notions: for example, instead of a definition of "affix", which needs to navigate through all the messy connotations that such a word raises, we end up with definitions like "element that subcategorizes for a stem class" or "element that undergoes segmental interaction with an adjacent element", etc. Such variables allow capturing rather than ignoring diversity, and they stand a greater chance to be codable in replicable ways across many languages. Fine-grained variables form just the right input for research on how structures distribute in the world, and, at the same time, they provide just the right tools for analyzing individual structures beyond futile naming exercises.

Moreover, once such detailed coding is available, diversity becomes directly measurable by the same tools that other disciplines, from biology to economics, have used standardly for decades: from a matrix of language-specific structures coded for a series of variables one can easily test covariation between variables and compute a matrix of (dis)similarities between structures. Such a matrix can be subject to the increasingly rich arsenal of clustering and scaling techniques that is now available from other disciplines (see, e.g., Cysouw 2006 for a recent survey) so as to find out whether some language-specific structures are more similar to each other than others, i.e., form crosslinguistic clusters. If there are such clusters, these then deserve the title "prototype" on an empirical ground, and obviously demand theoretical explanation. (But there is no guarantee of course that there are any clusters.)

This shifts the burden from debating universal definitions to developing finegrained, and therefore, increasingly precise, descriptive variables. In the end, the tasks of fieldwork merge entirely with the tasks that precede every project about large-scale distributions. This also confirms the observation made earlier 
that the variables developed in typology are and should be in close correspondence to those needed for fieldwork-based primary analysis.

\section{Conclusion}

Modern typology is a discipline that develops variables for capturing similarities and differences of structures both within and across languages (qualitative typology), explores clusters and skewings in the distribution of these variables (quantitative typology), and proposes theories that explain the clusters and skewings (theoretical typology). The ultimate goal is to understand "what's where why?", and this makes it clear that the major contributions that typology offers are not confined to Cognitive Science as narrowly understood. The goals of 21 st century typology are embedded in a much broader anthropological perspective: to help understand how the variants of one key social institution are distributed in the world, and what general principles and what incidental events are the historical causes for these distributions.

Received: 17 December 2005

Universität Leipzig Revised: 5 March 2007

Correspondence address: Institut für Linguistik, Universität Leipzig, Beethovenstraße 15, 04107 Leipzig, Germany; e-mail: bickel@uni-leipzig.de

Acknowledgements: This paper was originally presented at an invited panel "Typology in American Linguistics: An appraisal of the field" held after the 2005 meeting of the Linguistic Society of America in Oakland, California, and organized by Larry Hyman, Lynn Nichols, and Johanna Nichols. I thank the organizers, the other panel participants, and the audience for stimulating discussions. For helpful comments on an earlier draft, I am also indebted to Dik Bakker, Juliette Blevins, Joan Bresnan, Martin Haspelmath, Edith Moravscik, and Sabine Stoll. The views expressed here are my personal ones, and if there are any misrepresentations of the field, I take sole responsibility.

\section{References}

Baker, Mark C. (2002). The Atoms of Language: The Mind's Hidden Rules of Grammar. Oxford: Oxford University Press.

Baker, Mark C. \& Jim McCloskey (2007). On the relationship of typology to theoretical syntax. Linguistic Typology 11: 285-296.

Bakker, Dik (2004). LINFER and the WALS database. Paper presented at the "Workshop on Interpreting Typological Distributions", Leipzig, December 2004.

Bell, Alan (1978). Language samples. In Greenberg, Ferguson, \& Moravcsik (eds.) 1978, 123-156.

Berman, Ruth Aronson \& Dan I. Slobin (eds.) (1994). Relating Events in Narrative: A Crosslinguistic Developmental Study. Hillsdale, N.J.: Erlbaum.

Bickel, Balthasar (2000). Grammar and social practice: The role of "culture" in linguistic relativity. In Niemeier \& Dirven (eds.) 2000, 161-191.

- (2003). Referential density in discourse and syntactic typology. Language 79: 708-736. 
- (2007). A refined sampling procedure for genealogical control. Sprachtypologie und Universalienforschung.

Bickel, Balthasar, Martin Gaenszle, Arjun Rai, Prem Dhoj Rai, Shree Kumar Rai, Vishnu S. Rai, \& Narayan P. Sharma (Gautam) (2007). Two ways of suspending object agreement in Puma: Between incorporation, antipassivization, and optional agreement. Himalayan Linguistics 7: $1-18$.

Bickel, Balthasar \& Johanna Nichols (2003). Typological enclaves. Paper presented at the 5th biennial conference of the Association for Linguistic Typology, Cagliari, September 2003. http://www.uni-leipzig.de/ autotyp/download

- (2005). Inclusive/exclusive as person vs. number categories worldwide. In Elena Filimonova (ed.), Clusivity, 47-70. Amsterdam: Benjamins.

- (2006). Oceania, the Pacific Rim, and the theory of linguistic areas. Berkeley Linguistics Society 32. Available at http://www.uni-leipzig.de/ bickel/research/papers

- (2007). The AUTOTYP database. Electronic database. http://www.uni-leipzig.de/ autotyp

Blevins, Juliette (2004). Evolutionary Phonology: The Emergence of Sound Patterns. Cambridge: Cambridge University Press.

Bornkessel, Ina \& Matthias Schlesewsky (2006). The Extended Argument Dependency Model: A neurocognitive approach to sentence comprehension across languages. Psychological Review 113: 787-821.

Bornkessel, Ina, Stefan Zysset, Angela D. Friederici, D. Yves von Cramon, \& Matthias Schlesewsky (2005). Who did what to whom? The neural basis of argument hierarchies during language comprehension. NeuroImage 26: 221-233.

Bowerman, Melissa \& Stephen C. Levinson (eds.) (2001). Language Acquisition and Conceptual Development. Cambridge: Cambridge University Press.

Bybee, Joan (1988). The diachronic dimension in explanation. In Hawkins (ed.) 1988, 350-379.

- (2001). Phonology and Language Use. Cambridge: Cambridge University Press.

Comrie, Bernard (2005). Alignment of case marking. In Haspelmath et al. (eds.) 2005, 398-405.

Croft, William (2000). Explaining Language Change: An Evolutionary Approach. Harlow: Longman.

- (2002). Typology and Universals. Cambridge: Cambridge University Press.

Croft, William \& Keith T. Poole (2004). Inferring universals from grammatical variation: Multidimensional scaling for typological analysis. Manuscript, Center for Advanced Studies in the Behavioral Sciences, Stanford.

Cysouw, Michael (2005). Quantitative methods in typology. In Gabriel Altmann, Reinhard Köhler, \& Rajmund G. Piotrowski (eds.) Quantitative Linguistics: An International Handbook, 554578. Berlin: Walter de Gruyter.

- (2006). New approaches to cluster analysis of typological indices. Manuscript, Max PlanckInstitut für evolutionäre Anthropologie, Leipzig.

Dik, Simon C. (1978). Functional Grammar. Amsterdam: North-Holland.

Dryer, Matthew S. (1989). Large linguistic areas and language sampling. Studies in Language 13: 257-292.

- (1992). The Greenbergian word order correlations. Language 68: 81-138.

- (1997). Are grammatical relations universal? In Joan Bybee, John Haiman, \& Sandra A. Thompson (eds.), Essays on Language Function and Language Type Dedicated to T. Givón, 117-143. Amsterdam: Benjamins.

- (1998). Why statistical universals are better than absolute universals. Chicago Linguistic Society 33: 123-145.

- (2002). Case distinctions, rich verb agreement, and word order type (comments on Hawkins' paper). Theoretical Linguistics 28: 151-157.

- (2003). Word order in Sino-Tibetan languages from a typological and geographical perspective. In Graham Thurgood \& Randy J. LaPolla (eds.), The Sino-Tibetan Languages, 43-55. London: Routledge. 
- (2005). Order of subject, object, and verb. In Haspelmath et al. (eds.) 2005, 330-334.

Dunn, Michael J., Angela Terrill, Ger P. Reesink, Robert A. Foley, \& Stephen C. Levinson (2005). Structural phylogenetics and the reconstruction of ancient language history. Science 309: 2072-2075.

Enfield, N. J. (ed.) (2002). Ethnosyntax: Explorations in Grammar and Culture. Oxford: Oxford University Press.

Evans, Nicholas (2003). Context, culture, and structuration in the languages of Australia. Annual Review of Anthropology 32: 13-40.

Fortescue, Michael D. (1998). Language Relations across Bering Strait: Reappraising the Archaeological and Linguistic Evidence. London: Cassell.

Gensler, Orin (1993). A typological evaluation of Celtic/Hamito-Semitic syntactic parallels. Doctoral dissertation, University of California at Berkeley.

Gentner, Dedre \& Susan Goldin-Meadow (eds.) (2003). Language in Mind: Advances in the Study of Language and Cognition. Cambridge, Mass.: MIT Press.

Givón, Talmy (1979). On Understanding Grammar. New York: Academic Press.

Greenberg, Joseph H. (1965). Synchronic and diachronic universals in phonology. Language 42: 508-517.

- (1978). Diachrony, synchrony and language universals. In Greenberg, Ferguson, \& Moravcsik (eds.) 1978, 61-92.

Greenberg, Joseph H., Charles A. Ferguson, \& Edith A. Moravcsik (eds.) (1978). Universals of Human Language, Volume 1: Method \& Theory. Stanford: Stanford University Press.

Gumperz, John J. \& Stephen C. Levinson (eds.) (1996). Rethinking Linguistic Relativity. Cambridge: Cambridge University Press.

Hall, Christopher J. (1988). Integrating diachronic and processing principles in explaining the suffixing preference. In Hawkins (ed.) 1988, 321-349.

Haspelmath, Martin (1999). Optimality and diachronic adaptation. Zeitschrift für Sprachwissenschaft 18: 180-205.

- (2004). Does linguistic explanation presuppose linguistic description? Studies in Language 28: 554-579.

Haspelmath, Martin, Matthew S. Dryer, David Gil, \& Bernard Comrie (eds.) (2005). The World Atlas of Language Structures. Oxford: Oxford University Press.

Hawkins, John A. (2004). Efficiency and Complexity in Grammars. Oxford: Oxford University Press.

Hawkins, John A. (ed.) (1988). Explaining Language Universals. Oxford: Blackwell.

Hyman, Larry M. (2007). Where is phonology in typology? Linguistic Typology 11: 265-271.

Jakobson, Roman (1931 [1970]). K xarakteristike èvrazijskogo jazykovogo sojuza. Paris: Izdatel'stvo èvrazijcev. [Reprinted in Roman Jakobson, Selected Writings, Volume 1, 144-201. The Hague: Mouton.]

Janssen, Dirk, Balthasar Bickel \& Fernando Zúñiga (2006). Randomization tests in language typology. Linguistic Typology 10: 419-440.

Kirby, Simon (1999). Function, Selection, and Innateness. Oxford: Oxford University Press.

Levinson, Stephen C. (2003). Space in Language and Cognition. Cambridge: Cambridge University Press.

Levinson, Stephen C., Sergio Meira, \& The Language and Cognition Group (2003). "Natural concepts" in the spatial topological domain - adpositional meanings in crosslinguistic perspective: An exercise in semantic typology. Language 79: 485-516.

Lieven, Elena \& Sabine Stoll (in press). Language. In Mark Bornstein (ed.), Handbook of Crosscultural Developmental Science. Mahwah, N.J.: Erlbaum.

Lucy, John A. (1992). Grammatical Categories and Cognition. Cambridge: Cambridge University Press.

Masica, Colin P. (1976). Defining a Linguistic Area (South Asia). Chicago: University of Chicago Press. 
Maslova, Elena (2000). A dynamic approach to the verification of distributional universals. Linguistic Typology 4: 307-333.

Nettle, Daniel (1999). Linguistic Diversity. Oxford: Oxford University Press.

Newmeyer, Frederick J. (1998). The irrelevance of typology for grammatical theory. Syntaxis 1: 161-197.

- (2004). Typological evidence and Universal Grammar. Studies in Language 28: 527-548.

- (2005). Possible and Probable Languages: A Generative Perspective on Linguistic Typology. New York: Oxford University Press.

Nichols, Johanna (1992). Language Diversity in Space and Time. Chicago: University of Chicago Press.

- (1997). Modeling ancient population structures and population movement in linguistics and archeology. Annual Review of Anthropology 26: 359-384.

- (2007). What, if anything, is typology? Linguistic Typology 11: 231-238.

Nichols, Johanna \& David A. Peterson (1996). The Amerind personal pronouns. Language 72: 336-371.

Niemeier, Susanne \& René Dirven (eds.) (2000). Evidence for Linguistic Relativity. Amsterdam: Benjamins.

Perkins, Revere D. (1989). Statistical techniques for determining language sample size. Studies in Language 13: 293-315.

Plank, Frans (ed.) (2003). Das grammatische Raritätenkabinett. Electronic database, http://typo. uni-konstanz.de/rara/intro/

Plank, Frans \& Elena Filimonova (2000). The Universals Archive: A brief introduction to prospective users. Sprachtypologie und Universalienforschung 53: 109-123.

Plank, Frans \& Thomas Mayer (2006). The Universals Archive goes do-it-yourself. Linguistic Typology 10: 457-459.

Plank, Frans \& Wolfgang Schellinger (2000). Dual laws in no time. Sprachtypologie und Universalienforschung 53: 46-52.

Roberson, Debi, Jules Davidoff, Ian Davies, \& Laura R. Shapiro (2005). Color categories: Evidence for the cultural relativity hypothesis. Cognitive Psychology 50: 315-412.

Stilo, Donald L. (1987). Ambiposition as an areal response: The case study of the Iranian zone. In Elena Bashir, Madhav P. Deshpande, \& Peter E. Hook (eds.), Select Papers from SALA 7, 308-335. Bloomington: Indiana University Linguistics Club.

- (2005). Iranian as a buffer zone between the universal typologies of Turkic and Semitic. In Éva Ágnes Csató, Bo Isaksson, \& Carina Jahani (eds.), Linguistic Convergence and Areal Diffusion: Case Studies from Iranian, Semitic and Turkic, 35-63. London: RoutledgeCurzon.

van der Auwera, Johan (1998). Revisiting the Balkan and Meso-American linguistic areas. Language Sciences 20: 259-270.

Van Valin, Robert D., Jr. \& Randy J. LaPolla (1997). Syntax: Structure, Meaning, and Function. Cambridge: Cambridge University Press.

Wichmann, Søren \& David Kamholz (2007) A stability metric for typological features. Sprachtypologie und Universalienforschung 60. 